\title{
Experiência de projeto participativo para a sala de coleta de leite de um hospital da grande Florianópolis
}

\author{
Participatory design experience for a milk collecting room of a hospital in Florianópolis \\ - Maria Candelária Ryberg \\ Universidade Federal de Santa Catarina, Brasil \\ candelária.ryberg@gmail.com \\ Patrícia Biasi Cavalcanti \\ Universidade Federal de Santa Catarina, Brasil \\ patibiasi@yahoo.com \\ - Maria Luiza Bratti \\ Universidade Federal de Santa Catarina, Brasil \\ mluizabratti@hotmail.com \\ - Vera Helena Moro Bins Ely
Universidade Federal de Santa Catarina, Brasil
vera.binsely@gmail.com
}

\begin{abstract}
This article describes the experience of a participatory design project of a milk collecting room. The objective of this project was to identify the desirable attributes of the environment and contemplate participatory design applications. The methodology used includes: AEIOU, SWOT analysis, Brainstorming, Wish Poems, interaction with the proposals using 3D modeling and Visual Selection. The present work confirms the benefits of the participatory process as a possibility to expand the comprehension of the user's needs. Moreover, the project proved that digitalized graphic resources are easy to use and are beneficial to interaction with the present proposal.
\end{abstract}

Keywords: Participatory Design, Interior Design, Health Care Enviroments, Milk Bank

\section{Introdução}

Estudos sobre a influência do ambiente físico no comportamento e no bem-estar dos usuários evidenciam a importância de se compreender suas necessidades e anseios. Desdeosanos 70, grandeênfase tem sido dada ao planejamento de ambientes de saúde humanizados, isso é, centrados nas expectativas e necessidades de seus usuários. Com a humanização pretende-se qualificar estes ambientes, de forma a desvinculá-los de imagens negativas usualmente associadas aos hospitais e assegurar atributos ambientais desejáveis a sua apropriação. Busca-se criar condições favoráveis ao atendimento à saúde pelos profissionais, à recuperação dos pacientes e à acomodação dos acompanhantes, favorecendo uma experiência mais positiva do local por todos (ROCHA, 2010; CAVALCANTI, 2009; VASCONCELOS, 2004).

Os ambientes ligados ao nascimento são vivenciados pelos usuários de forma diferenciada, uma vez que o seu públicoalvo tende a apresentar condições mais amenas e positivas do que os usuários de outras unidades hospitalares. Nos Bancos de Leite e suas salas de coleta são realizadas atividades relacionadas ao aleitamento materno, estimulando-se a vinda de lactantes que serão doadoras. Visto a importância do leite materno para os bebês que receberão a doação, imagina-se que o planejamento de interiores deve criar uma ambiência que responda a especificidade de seu público usuário, refletindo suas necessidades, anseios e expectativas.
Apesar da compreensão da importância do desenvolvimento de projetos cada vez mais centrados em seus usuários, especialmente em ambientes coletivos, a participação dos mesmos no processo projetual ainda é rara em Arquitetura e Design de Interiores. A busca por soluções mais responsivas tem instigado arquitetos a adotarem métodos de projeto participativo, por possibilitarem uma compreensão mais aprofundada das necessidades dos usuários, favorecendo a apropriação e a satisfação quanto ao espaço projetado (SANOFF, 1981; SANOFF, 1985; SANOFF, 1988). Neste sentido, buscou-se contribuir para a compreensão do tema por meio da realização de uma experiência de projeto participativo para a reforma e design de interiores de uma sala de coleta de leite de um hospital de Florianópolis, Santa Catarina - Brasil.

\section{Metodologia}

Neste trabalho buscou-se tanto avaliar e testar a aplicabilidade de alguns métodos participativos em um projeto de reforma e interiores, quanto investigar quais os atributos ambientais desejáveis para o planejamento de Salas de Coleta de Leite.

Para tanto foram realizados dois workshops participativos, visando compreender anseios e necessidades de lactantes, funcionários e acompanhantes em relação ao planejamento do ambiente. Além disso,previamente aos workshops, e buscando uma aproximação maior com o objeto de estudo, 
foram aplicados os seguintes métodos: revisão de literatura, AEIOU e Análise SWOT.

$O$ método AEIOU consiste em registrar os dados da observação direta e sistemática do ambiente em cinco formulários distintos, sendo cada um deles referente a uma das categorias a seguir: Atividades, Espaço, Interações, Objetos e Usuários (MARTIM; HANINGTON, 2012). Com base nos dados obtidos por meio da AEIOU e também em uma entrevista nãoestruturada com a chefia da Unidade, foi realizada a análise SWOT. Este método, por sua vez, consiste em organizar os dados obtidos em uma tabela, através da listagem das forças (Strenghts), fraquezas (Weaknesses), oportunidades (Opportunities) e ameaças (Threats), subdivididas ainda em fatores internos e externos. Com a análise SWOT podese obter uma análise crítica das informações levantadas e identificar desafios, limitações e potencialidades do local de estudo para o projeto a ser desenvolvido (NUCCI, 2012).

Com os dois workshops participativos buscou-se estimular sua participação em diferentes momentos do processo projetual. No primeiro workshop foi aplicado o Brainstorming visando definir o conceito geral da proposta a ser desenvolvida. Totalizaram 15 participantes, entre eles: 10 profissionais da saúde, 2 bolsistas e 1 arquiteto do hospital, e 2 funcionários que não se identificaram. Em seguida, foi aplicado o Poema dos Desejos, dessa vez visando compreender expectativas e anseios mais específicos dos usuários em relação à sala, de forma a ter diretrizes detalhadas que orientassem o processo projetual.

Entre o primeiro e o segundo workshop a equipe de pesquisadoras desenvolveu diferentes alternativas projetuais, centradas nos usuários. No segundo workshop houveram 10 participantes, entre eles: 5 profissionais da saúde, 2 mães e 2 assistentes sociais e 1 psicóloga. Neste workshop, foi utilizado um método dinâmico, desenvolvido pelas próprias pesquisadoras, para apresentar três alternativas aos participantes e permitir aos mesmos refletir sobre elas, argumentar, selecionar a que mais lhe agradava e ainda propor ajustes. As mesmas foram apresentadas por meio de plantas-baixas e perspectivas isométricas feitas através do software Sketchup. Cada componente do ambiente foi impresso separadamente e plastificado, de forma a ser manipulado pelos participantes, que podiam acrescentá-lo, retirálo ou mudar sua posição em cada proposta apresentada. Com isso, buscou-se facilitar a interação dos participantes com as alternativas apresentadas. Em seguida, iniciouse a argumentação para chegar-se ao consenso de qual alternativa estava melhor adaptada às atividades e expectativas desses usuários (SANOFF, 1988). Após escolhida a alternativa e expostos os ajustes necessários a ela, foi aplicado o método de Seleção Visual no qual os participantes deviam apontar suas preferências em relação a algumas possibilidades de soluções projetuais para ambientação e acabamentos, dando suporte a elaboração do projeto executivo de interiores.

\section{Resultados e Discussões}

A técnica AEIOU permitiu a observação de diferentes aspectos do ambiente - atividades, espaço, interações, objetos e usuários. As percepções referentes a cada item são apresentadas na tabela abaixo.

\begin{tabular}{|c|c|}
\hline Atividades & $\begin{array}{l}\text { Quanto às Atividades, foi possível observar as } \\
\text { rotinas no ambiente o que inclui: a ordenha } \\
\text { do leite pelas mães e lactantes, o auxílio deste } \\
\text { processo pelas enfermeiras e alunas bolsistas, e } \\
\text { a limpeza da sala pelas funcionárias. }\end{array}$ \\
\hline Espaço & $\begin{array}{l}\text { A observação do Espaço evidenciou que o } \\
\text { mesmo é pequeno para as diversas atividades } \\
\text { nele realizadas. A má-distribuição do mobiliário } \\
\text { dificulta tanto a circulação quanto o auxílio das } \\
\text { funcionárias às mães no momento da ordenha. } \\
\text { A proximidade e a falta de uma barreira visual } \\
\text { entre as cadeiras de ordenha comprometiam } \\
\text { a privacidade das mães e doadoras. Além } \\
\text { disso, o ambiente passa uma imagem pouco } \\
\text { acolhedora, ocasionada pelas cores sóbrias, } \\
\text { pela iluminação inadequada, pela falta de } \\
\text { elementos de ambientação e pelo estado de } \\
\text { conservação ruim dos objetos e acabamentos. }\end{array}$ \\
\hline Interações & $\begin{array}{l}\text { As Interações se referem às trocas sociais } \\
\text { realizadas entre as pessoas ou a relação dessas } \\
\text { com os objetos e o espaço. Foi possível observar } \\
\text { queas lactantesque utilizavam essa sala tinham } \\
\text { interações mais fortes entre si do que com as } \\
\text { próprias funcionárias ou visitantes, uma vez } \\
\text { que aquelas permanecem por mais tempo } \\
\text { no ambiente. Elas também demonstraram } \\
\text { ter grande autonomia e independência na } \\
\text { utilização do ambiente e na realização de suas } \\
\text { atividades. }\end{array}$ \\
\hline Objetos & $\begin{array}{l}\text { Na sala estudada, pôde-se notar que muitos dos } \\
\text { Objetos eram antigos, deteriorados pelo tempo } \\
\text { e uso. Os móveis e equipamentos eletrônicos } \\
\text { não se adéquam ao espaço, muitas vezes não } \\
\text { cumprindo a sua função e comprometendo } \\
\text { a circulação. O mobiliário se mostrou ainda } \\
\text { pouco ergonômico. }\end{array}$ \\
\hline Usuários & $\begin{array}{l}\text { Pode-se observar que os Usuários da sala são } \\
\text { principalmente: mulheres jovens e adultas que } \\
\text { possuem filhos internados na UTI Neonatal; } \\
\text { mães externas ao hospital com dificuldades de } \\
\text { amamentar; doadoras de leite; enfermeiras e } \\
\text { técnicas de enfermagem; estudantes e bolsistas } \\
\text { da área da saúde; e outras funcionárias. } \\
\text { Também é comum a presença de visitantes, } \\
\text { como familiares das mães ou pais dos bebês } \\
\text { internados, que oferecem suporte social as } \\
\text { lactantes. }\end{array}$ \\
\hline
\end{tabular}

Tabela 1: Tabela resumo dos resultados da técnica AEIOU. Fonte: autoria nossa, 2014. 
Os dados obtidos a partir da aplicação do AEIOU e da entrevista com a chefia da Unidade foram sintetizados por meio da Análise SWOT, como segue abaixo.

\begin{tabular}{|c|c|}
\hline \multicolumn{2}{|c|}{ FATORES INTERNOS } \\
\hline PONTOS FORTES & PONTOS FRACOS \\
\hline $\begin{array}{l}\text { Além da coleta de leite, } \\
\text { também realizam- } \\
\text { se no local funções } \\
\text { educacionais associadas } \\
\text { ao aleitamento } \\
\text { materno; } \\
\text { A sala é própria para o } \\
\text { atendimento; } \\
\text { Dispõem de } \\
\text { equipamentos como } \\
\text { ar-condicionado SPLIT, } \\
\text { geladeira e televisão; }\end{array}$ & $\begin{array}{ll}\text { - } & \text { Espaço físico } \\
\text { insuficiente para todas } \\
\text { as atividades; } \\
\text { - Ausência de sala de } \\
\text { espera; } \\
\text { - } \quad \text { Ausência de distrações } \\
\text { positivas; } \\
\text { - } \quad \text { Mobília depredada e } \\
\text { pouco confortável; } \\
\text { - Acabamentos não } \\
\text { - } \quad \text { Maguem distribuição da } \\
\text { mobília compromete a } \\
\text { circulação. }\end{array}$ \\
\hline \multicolumn{2}{|c|}{ FATORES EXTERNOS } \\
\hline AMEAÇAS & OPORTUNIDADES \\
\hline $\begin{array}{l}\text { - Insolação direta muito } \\
\text { - } \quad \text { Farte; } \\
\text { são furtados, na há } \\
\text { controle do acesso); } \\
\text { - Falta privacidade visual } \\
\text { em relação ao exterior; } \\
\text { - Possui ruídos } \\
\text { constantes, como } \\
\text { o barulho dos ar- } \\
\text { condicionados. }\end{array}$ & $\begin{array}{l}\text { - A sala está } \\
\text { localizada próxima } \\
\text { à Neonatologia, ao } \\
\text { Alojamento Conjunto e } \\
\text { à Unidade Canguru; } \\
\text { - A sala apresenta boa } \\
\text { iluminação natural. }\end{array}$ \\
\hline
\end{tabular}

Tabela 2: Análise SWOT. Fonte: autoria nossa, 2014.

Com base nos resultados obtidos nesta análise prévia, foram planejados os dois workshops participativos. Dentre os resultados do primeiro workshop participativo, destacaramse três atributos ambientais para nortear o planejamento de uma sala de coleta de leite: a privacidade, o aconchego e a funcionalidade. A privacidade mostrou-se fundamental para garantir o bem-estar e o conforto das lactantes. Tendo em vista que a ordenha de leite é a principal atividade realizada, faz-se necessário resguardar as mulheres que a realizam dos olhares de terceiros, que podem ser funcionários ou acompanhantes que adentram o local. Nas propostas desenvolvidas, a privacidade visual foi prevista por meio de boxes individuais para a ordenha do leite, com divisórias entre eles. Isso implicou numa redução no número de poltronas de ordenha que existiam no local, mas confirmou-se como a principal demanda dos usuários. A compartimentação do ambiente favorece ainda a privacidade acústica, resguardando conversas entre os profissionais de saúde e os demais usuários.

A funcionalidade foi outro atributo que se destacou durante o processo. Com ela busca-se proporcionar uma configuração ambiental que favoreça a realização das atividades, rotinas e fluxos no local. Cabe observar que como a sala estudada tem dimensões bastante reduzidas, o planejamento do layout e do mobiliário teve de ser coerente com todas as atividades realizadas. Além disso, cada armário foi projetado cuidadosamente para acomodar determinados insumos utilizados no local.

O acolhimento, por sua vez, mostrou-se fundamental pela natureza do ambiente e perfil dos usuários. Ordenhar o leite e amamentar são atividades delicadas, de grande importância para os bebês e fundamentais para o funcionamento do Banco de Leite. Uma ambiência acolhedora, aconchegante e convidativa, que estimule a permanência prolongada das lactantes no local, mostra-se desejável para o sucesso desta Unidade Hospitalar.

Com o Poema dos Desejos foi solicitado aos participantes desenhassem e/ou descrevessem o ambiente de forma mais detalhada possível, mencionando tudo que desejavam que estivesse presente na sua requalificação. Foi realizada uma categorização dos resultados, por meio de Análise de Conteúdo, no sentido de compreender que atributos ambientais são mais importantes para os usuários. Foram criadas categorias de respostas relativas a aspectos repetitivos ou similares, de forma a evidenciar que elementos eram mencionados com maior freqüência pelos participantes. Dentre os elementos citados, destacaram-se: a necessidade de cadeiras confortáveis (mencionadas por 49\% dos participantes), divisórias retráteis entre as cadeiras de ordenha e o uso de tons claros (ambos mencionadas por 35\% dos participantes), e a presença de uma televisão mais moderna e iluminação individualizada (ambas mencionadas por $28 \%$ dos participantes).

No segundo workshop, foram apresentadas três alternativas projetuais desenvolvidas com base nos resultados do primeiro workshop. Foi neste momento, que cada proposta foi apresentada tanto em planta-baixa humanizada quanto por meio de duas perspectivas isométricas, tendo sido os desenhos elaborados com o software Sketchup. A forma de apresentação destes desenhos, onde cada elemento era fixado individualmente, permitia a todos interagirem com as alternativas projetuais, modificando-as, experimentando e propondo ajustes.

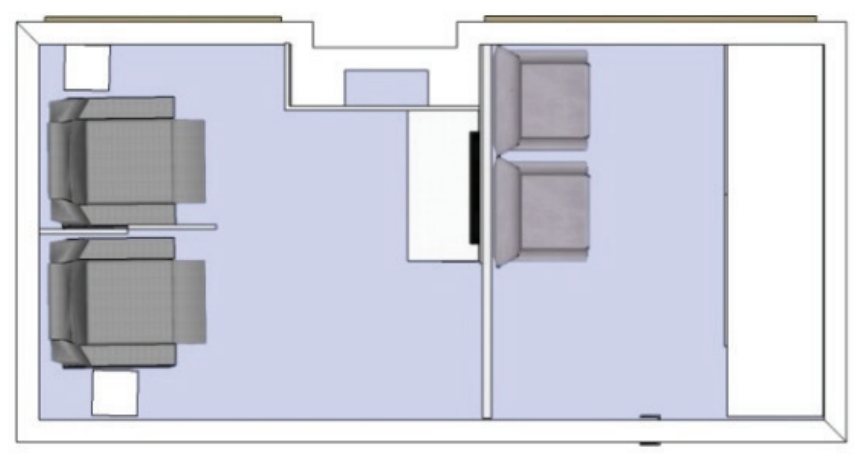

Figura 1: Proposta de layout 1. Fonte: autoria nossa, 2014. 


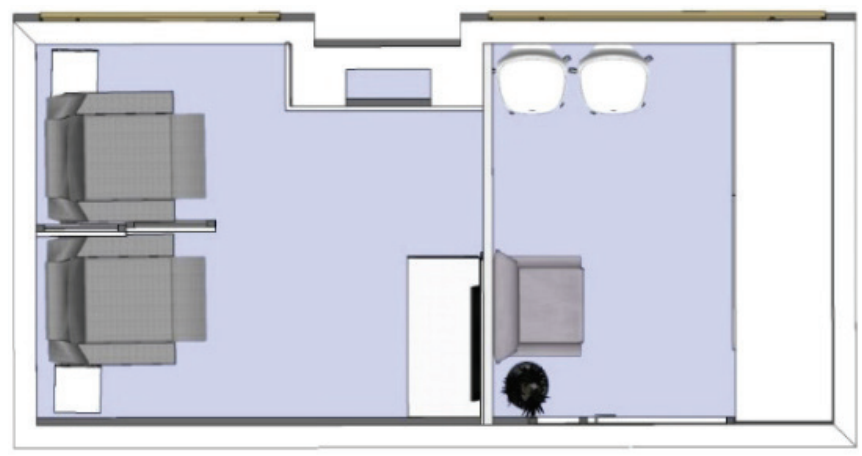

Figura 2: Proposta de layout 2. Fonte: autoria nossa, 2014.

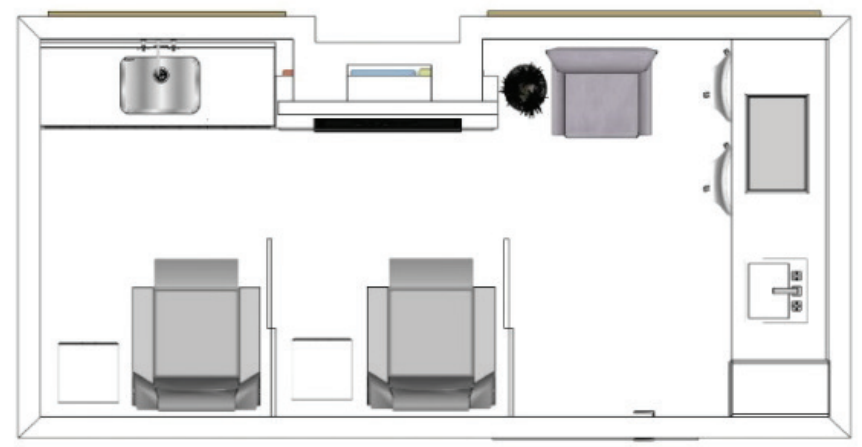

Figura 3: Proposta de layout 3. Fonte: autoria nossa, 2014.

Após longa argumentação, o grupo de participantes escolheu a Proposta 1, por proporcionar a separação da sala em dois ambientes, priorizando a privacidade das mães enquanto realizam a ordenha, e também devido a maior quantidade de cadeiras disponíveis.

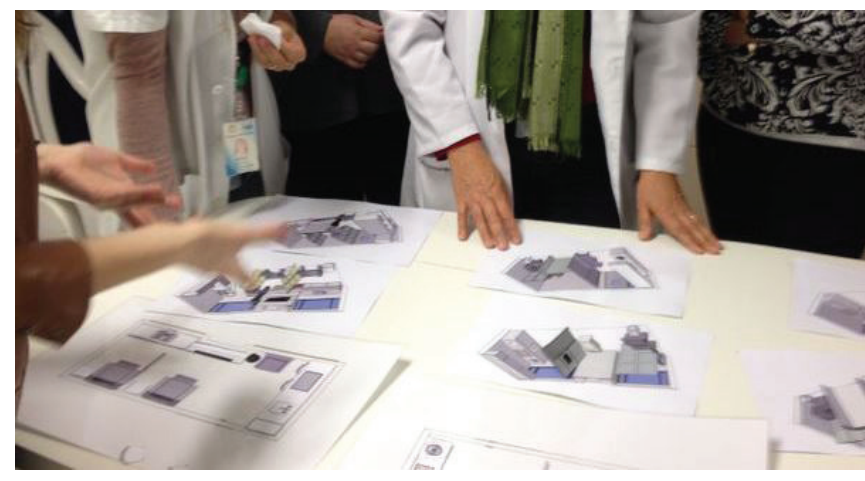

Figura 4: Imagem da atividade para discussão do layout, realizado no segundo workshop participativo. Fonte: autoria nossa, 2014.

Em seguida, ainda no segundo workshop, foram entregues fichas de Seleção Visual aos participantes, apresentando estilos variados de elementos de ambientação e acabamentos, com o intuito de identificar quais as suas preferências. Os resultados foram coerentes com os conceitos definidos no primeiro workshop. Foi demonstrado um desejo por um ambiente acolhedor, remetendo a uma imagem maternal e feminina, com tons claros, em uma paleta de rosa, verde e marfim.
Também se destacou a preferência por móveis com detalhes simples e contínuos, práticos e de fácil limpeza, sem relevos e ornamentos. Já em relação à ambientação os participantes optaram por iluminação embutida, e a disposição na parede de fotos adesivadas, gravuras ou quadros.

Com o término dos workshops participativos, a equipe desenvolveu o projeto executivo para a Sala de Coleta de Leite, com todos os aspectos levantados durante o processo. $\mathrm{O}$ projeto de interiores foi montado como um caderno no formato A3 e apresentado em uma reunião com a direção do Hospital, a equipe da Sala de Coleta de Leite e os demais participantes dos workshops.

\section{Considerações Finais}

A utilização dos métodos de projeto participativo certamente contribuiu para melhor compreender o perfil dos usuários, as atividades desenvolvidas e as características desejáveis para o planejamento do ambiente. Neste local, diferentemente de outros setores do hospital, não são realizadas atividades críticas de atendimento à saúde. Possivelmente por este motivo, assegurar a privacidade das lactantes e uma ambientação acolhedora destacou-se como dois dos principais atributos ambientais desejados, em detrimento de outros aspectos como infra-estrutura ou questões técnico-construtivas.

Durante os Workshops participativos, notou-se a necessidade de desenvolver-se um método expositivo para a apresentação das propostas de layout desenvolvidas. Tradicionalmente, em projetos participativos, são utilizadas maquetes para este fim. No entanto, por tratar-se de projeto de interiores, havia muitos detalhes em cada alternativa projetual que seriam difíceis de caracterizar corretamente em um modelo reduzido. Por isso, optou-se por utilizar plantasbaixas e isométricas de cada alternativa, representadas com o uso do software Sketchup, em que cada elemento da proposta foi impresso e emplastificado separadamente. Assim, tornou-se fácil para todos os participantes compreender as alternativas e realizar ajustes no mobiliário e objetos, retirando-os, movimentando-os ou acrescentando novos elementos.

A adoção de metodologias de projeto participativo é ainda rara em Arquitetura e Interiores no país, principalmente por demandar um tempo maior para o processo projetual do que a prática usual da maioria dos escritórios que atuam na área. Este acréscimo de tempo pode ser inviável em obras de caráter urgente ou elevar os custos dos honorários profissionais, afetando a competitividade do valor do serviço. Porém, sem dúvida, esta abordagem proporciona aos profissionais um entendimento aprofundado das necessidades e aspirações dos usuários, ao mesmo tempo em que favorece a todos os participantes tomarem consciência das necessidades dos demais em relação ao local. Tais benefícios certamente contribuem para sua identificação com o produto final, maior nível de satisfação em relação à proposta e para a responsividade do projeto. 


\section{Referências}

Adams, W. G. (1998). Participatory programming for Digital Equipment Corporation, INC. Design Studies. In: Sanoff, H. (1990). Participatory Design: Theory \& Technique. (pp. 110119). EUA: North Caroline State University.

Cavalcanti, P. B. (2011). A Humanização De Unidades Clínicas De Hospital-Dia: Vivência e Apropriação Pelos Usuários. (Tese de Doutorado, Universidade Federal do Rio de Janeiro, Brasil). Lawrence, $R$ (1987). Basic principles for public participation in house planning. Design Studies, 8 (2), 102-108, abr. In: Sanoff, H. (1990). Participatory Design: Theory \& Technique. (pp. 7682). EUA: North Caroline State University.

Luck, R. (2003). Dialogue in participatory design. Design Studies. 24 (6), 523-535.

Martin, B; Hanington, B. (2012) Universal Methods of Design: 100 Ways to Research Complex Problems, Develop Innovative Ideas, and Design Effective Solutions. (pp. 10-11). Estados Unidos: Rockport Publishers,.

Nucci, A. L. C. (2012) "DNA" Arquitetônico: conceitos de design aplicados ao método para reabilitação dos Espaços da arquitetura. (Mestrado em Arquitetura, Universidade Federal de Santa Catarina, Brasil),

Oberfer, J. (1988) Community participation in the design of
Boulder Creek Branch Library. Design Studies Santa Cruz, 9 (1), 4-13. In: Sanoff, H. (1990). Participatory Design: Theory \& Technique. (pp.110-119). EUA: North Caroline State University. Rocha, J.L.(2010). Humanização De Maternidades Públicas:Um Estudo Sobre A Arquitetura Das Enfermarias De Alojamento Conjunto. (Mestrado em Arquitetura, Universidade Federal de Santa Catarina, Brasil).

Sanoff, H. (1981). Human exchange techniques for citizen participation in town revitalization. Design Studies, 2 (3), 157-164. In: (1990). Participatory Design: Theory \& Technique. (pp. 83-91). EUA: North Caroline State University. (1988). Participatory Design in Focus. Architecture and Behavior, 4 (1). 1988. In: _-_-_-_. (1990). Participatory Design: Theory \& Technique. (pp. 5-20). EUA: North Caroline State University. (1985). The application of participatory methods in design and evaluation. Design Studies. 6 (4), 1-3. In: (1990). Participatory Design: Theory \& Technique. (pp. 5-20). EUA: North Caroline State University.

Vasconcelos, R. T. B. (2014). Humanização de Ambientes Hospitalares: Características Arquitetônicas Responsáveis pela Integração Interior/Exterior. (Mestrado em Arquitetura, Universidade Federal de Santa Catarina, Brasil). 